\title{
Can Traditional Theories of Structural Change Fit the Data?
}

\author{
Francisco J. Buera*and Joseph P. Kaboski ${ }^{\dagger}$
}

November 7, 2008

\begin{abstract}
Two traditional explanations for structural changes are sector-biased technological progress and non-homothetic preferences. This paper integrates both into an otherwise standard growth model and quantitatively evaluates them vis-a-vis time series. The exercise identifies a set of puzzles for standard theories: (i) the model cannot account for the steep decline in manufacturing and rise in services in the later data; (ii) the standard model requires implausibly low elasticity of substitution across goods to match the consumption and output data; and (iii) the behavior of consumption and output shares differs significantly from that of employment shares. We argue that models that incorporate home production, sector-specific factor distortions, and differences across sectors in the accumulation of human capital are promising avenues to amend the standard models.
\end{abstract}

*UCLA, fjbuera@econ.ucla.edu

${ }^{\dagger}$ Ohio State University and Federal Reserve Bank of Chicago, kaboski.1@osu.edu 


\section{Introduction}

Structural change has long been considered an integral part of the process of growth and development. The traditional literature dating back to the 19th century conjectured that either Engel's law (e.g., Engel, 1897, Houthakker, 1957), biased productivity growth (e.g., Baumol, 1967), or some combination account for sectoral trends in output and labor across agriculture, industry and services. ${ }^{1}$ Two recent works have formalized and extended these ideas to reconcile structural change with standard growth models consistent with otherwise balanced growth. Kongsamut et al. (2001) and Ngai and Pissarides (2007) give particular models in which non-homothetic preferences and biased productivity growth, respectively, yield structural change along with constant growth rates of output and consumption.

Theoretically, we show that these balanced growth predictions cannot be reconciled in an integrated model where both non-homothetic preferences and biased productivity growth affect the structure of production. Nonetheless, the exercise of this paper is to combine these two explanations to see whether such a model can do reasonably well quantitatively in matching the data. We also quantify the relative merits of demand and supply explanations. The exercise highlights important shortcomings of traditional explanations, including an inability to account for observed sectoral movements, a need for an unrealistic elasticity of substitution, and a discrepancy in the data between trends in sectoral labor shares and trends in sectoral output shares. We show that models incorporating frictions and/or human capital may be important in reconciling these puzzles, and we conjecture that considering higher levels of disaggregation and the home production margin may also be fruitful.

\section{Model}

We study a general framework integrating non-homothetic preferences and biased productivity/price movements that aggregates into a standard Neoclassical Growth Model. We then integrate distortions and average human capital levels that potentially differ across sectors.

\footnotetext{
${ }^{1}$ See Matsuyama (2008) for a recent review of this literature.
} 


\subsection{Preferences}

The representative agent has preferences over sequences of consumption vectors $c=\left\{\left\{c_{i t}\right\}_{i=a, m, s}\right\}_{t=0}^{\infty}$ represented by the following utility function

$$
U(c)=\sum_{t=0}^{\infty} \beta^{t} v\left(c_{a t}, c_{m t}, c_{s t}\right)^{1-\sigma} /(1-\sigma)
$$

where

$$
v\left(c_{a t}, c_{m t}, c_{s t}\right)=\left[\sum_{i=a, m, s} \gamma_{i}\left(c_{i t}-\bar{c}_{i}\right)^{(\varepsilon-1) / \varepsilon}\right]^{\varepsilon /(\varepsilon-1)}
$$

Consumer's Problem Given sequences of prices, $\left\{p_{i t}\right\}_{i=a, m, s}, w_{t}$, and $R_{t}, t=0, \ldots$, and human capital $h$, the representative agent chooses sequences of consumption vectors $\left\{\left\{c_{i t}\right\}_{i=a, m, s}\right\}_{t=0}^{\infty}$ and capital accumulation $I_{t}, k_{t}$ to maximize (1) subject to a standard budget constraint

$$
\sum_{i=a, m, s} p_{i t} c_{i t}+p_{m t} I_{t} \leq R_{t} k_{t}+w_{t} h
$$

and the law of motion for capital

$$
k_{t+1}=(1-\delta) k_{t}+I_{t}
$$

To show its relationship to the Neoclassical growth model, it is useful to rewrite the representative agent's problem as the following alternative program.

Equivalent Consumer's Problem Given sequences of prices, $\left\{p_{i t}\right\}_{i=a, m, s}$, $w_{t}$, and $R_{t}, t=0, \ldots$, the representative agent chooses sequences of consumption expenditures net of the value of consumption requirements, $c_{t}$, and capital accumulation $I_{t}, k_{t}$ to maximizes

$$
\sum_{t=0}^{\infty} \hat{\beta}_{t} c_{t}^{1-\sigma} /(1-\sigma)
$$

subject to a standard budget constraint

$$
p_{m t} c_{t}+p_{m t} I_{t} \leq R_{t} k_{t}+w_{t} h-\sum_{i=a, m, s} p_{i t} \bar{c}_{i}
$$


and the law of motion for capital, $k_{t+1}=(1-\delta) k_{t}+I_{t}$, where $c_{t}=\sum_{i} p_{i} c_{i t}-$ $\sum_{i} p_{i} \bar{c}_{i t}$ and $\hat{\beta}_{t}=\beta^{t}\left[\sum_{i}\left(\frac{\gamma_{i}}{\gamma_{m}}\right)^{\varepsilon}\left(\frac{p_{i t}}{p_{m t}}\right)^{1-\varepsilon}\right]^{(1-\sigma) /(\varepsilon-1)}$.

The following proposition characterizes the of parameter values for which structural change is consistent with balanced growth.

Proposition 1 In this economy structural change is consistent with balanced growth if and only if

(a) $\left(\bar{c}_{a}, \bar{c}_{m}, \bar{c}_{s}\right) \neq 0, \varepsilon=1$ and $\sum_{i} p_{i t} \bar{c}_{i}=0$ all $t$ (Kongsamut et al., 2001), or

(b) $p_{i t+1} / p_{i t} \neq p_{i^{\prime} t+1} / p_{i^{\prime} t}$ for some $i \neq i^{\prime}, \sigma=1$ and $\sum_{i} p_{i t} \bar{c}_{i}=0$ all $t$ (Ngai and Pissarides, 2007)

The consumer's problem is already quite insightful. Proposition 1 states that the non-homothetic preference story of Kongsamut et al. (2001) and the biased productivity growth story of Ngai and Pissarides (2007) are special cases of our model that lead to structural change and balanced growth. Interestingly, they are also mutually exclusive cases, since (b) requires that $\bar{c}_{i}=0$ for all sectors with changing relative prices.

Finally, in both special cases $c_{t}=\sum_{i} p_{i} c_{i t}$ and $\hat{\beta}_{t}=\beta^{t}$, so that both models reduce to the standard growth model. That is, while both models produce balanced growth, they also produce structural change that is not particularly important to overall welfare. Structural change is of secondary interest, since a simple aggregate model tells us all we need to know about growth.

\subsection{Technologies}

In order to get predictions for output and labor in this section we specify a model of technologies and policies.

Sector $i$ 's output is produced with a standard Cobb-Douglas technology:

$$
Y_{i}=A_{i} K_{i}^{\alpha}\left(h_{i} L_{i}\right)^{1-\alpha}
$$

where $A_{i}$ is the total factor productivity (TFP), $K_{i}$ the amount of capital used, $L_{i}$ the workforce employed, and $h_{i}$ the average human capital. We assume that sectors differ in their TFP $\left(A_{i}\right)$ and the average human capital of their workforce $\left(h_{i}\right)$. We assume that the three broad sectors have similar factor intensity $(\alpha)$, which is consistent with data (See Valentinyi and Herrendorf, 2007a). 
We consider a competitive equilibrium of this economy, in which capital and the workforce are endogenously allocated across sectors. We allow firms to face sector-specific distortions $\tau_{k}^{i}$ and $\tau_{w}^{i}$ to capital and labor, respectively. Such distortions potentially give structural change first-order importance, since they allow for aggregate output gains from reallocation.

Firm's Problem Firms in sector $i$ choose capital and labor inputs to maximize profits:

$$
\max _{k_{i}, h_{i}, l_{i}} p_{i} A_{i} K_{i}^{\alpha}\left(h_{i} L_{i}\right)^{1-\alpha}-\left(1+\tau_{k}^{i}\right) R K_{i}-\left(1+\tau_{w}^{i}\right) w h_{i} L_{i} .
$$

The following two propositions follow from the necessary conditions of the firm's problem.

Proposition 2 The model implies the following relationship between values added shares $\left(y_{i}\right)$, labor shares $\left(l_{i}\right)$, the average human capital $\left(h_{i}\right)$ and labor distortions $\left(\tau_{w}^{i}\right)$ :

$$
y_{i}=p_{i} Y_{i} /\left(\sum_{j} p_{j} Y_{j}\right)=h_{i}\left(1+\tau_{l}^{i}\right) l_{i} /\left(\sum_{j} h_{j}\left(1+\tau_{l}^{j}\right) l_{j}\right)
$$

where $l_{i}=L_{i} /\left(\sum_{j} L_{j}\right)$.

In the absence of human capital differences and differential distortions (i.e., $\tau_{l}^{i}=\tau_{l}^{j}$ and $h_{i}=h_{j}$ ), value-added shares and labor shares are equal. To the extent that the two deviate, human capital differences and distortions are quantitatively important, and raw labor shares may be less meaningful.

Proposition 3 The model implies the following relationship between relative prices $\left(p_{i}\right)$, TFP $\left(A_{i}\right)$ and input distortions $\left(\tau_{k}^{i}, \tau_{w}^{i}\right)$ across two sectors $i \neq i^{\prime}$ :

$$
p_{i} / p_{i^{\prime}}=\left(A_{i^{\prime}} / A_{i}\right)\left[\left(1+\tau_{k}^{i}\right) /\left(1+\tau_{k}^{i^{\prime}}\right)\right]^{\alpha}\left[\left(1+\tau_{l}^{i}\right) /\left(1+\tau_{l}^{i^{\prime}}\right)\right]^{1-\alpha}
$$

Here we show the link between relative prices and relative productivities and distortions. Again, in the absence of distortions relative prices reflect relative productivities.

\section{Structural Change: US 1870-2000}

In order to evaluate the roles of non-homotheticities and biased productivity, we set all distortions to zero, and equate human capital levels across sectors. 
We calibrate the model to minimize the (unweighted) sum of squared errors between the model and the time series data on output, current-price valueadded shares, and relative prices for the U.S. 1870-2000.

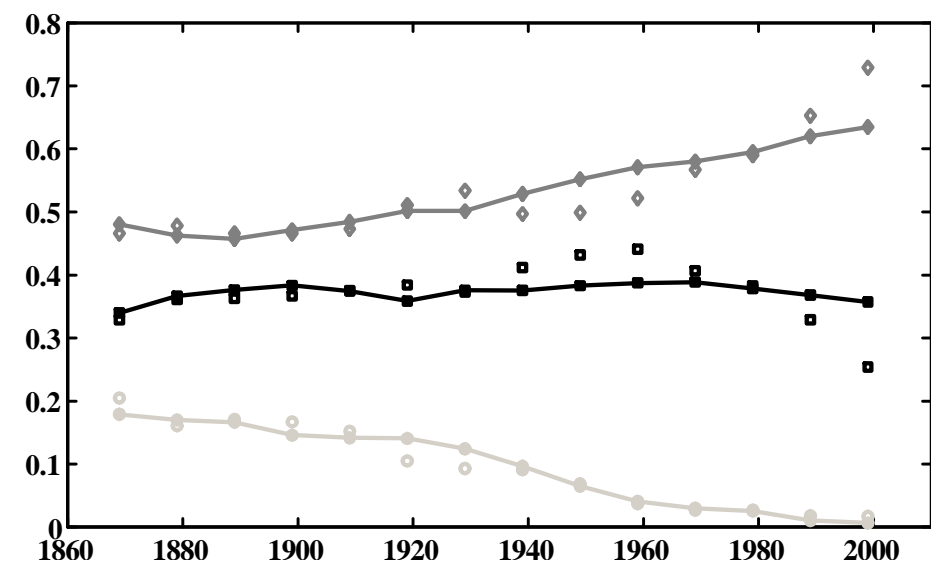

Figure 1: Evolution of value-added shares: agriculture (data: circles; model: line-circles), manufacturing (squares; line-squares), services (diamonds; linediamonds). United States, 1860-2000.

Figure 1 shows how the calibrated model's fit of the sectoral value-added share data. The solid line represents the calibrated of the model, while the dots represent the data. The model calibrates a substantial subsistence requirement for agriculture $\left(\bar{c}_{a}=0.0048\right)$, a sizable basic endowment of services $\left(\bar{c}_{s}=0.0062\right)$, and no consumption requirement for manufacturing. ${ }^{2}$ We calibrate an elasticity of substitution of $0.5 .^{3}$

While the model does reasonably well for agriculture, with the subsistence requirement playing the central role, the fit is poor for industry and services. The model fails to match the sharper increase in services and decline in manufacturing after 1960. A major problem is that the relative price of services to industry was rising during this period but at a slower rate than the relative shares. Thus, in this later period, both the relative quantity and relative price of services were rising relative to industry. Explaining

\footnotetext{
${ }^{2}$ The consumption requirement of agricultural goods amounts to $16 \%$ of per-capita income in 1860, while the endowment of services (negative consumption requirement) amounts to $12 \%$ of 1860 per-capita income.

${ }^{3}$ If unconstrained, the best fit of the model would required Leontieff preferences $(\varepsilon \rightarrow 0)$. Since the fit of the model does not improves substantially, we choose a low but more reasonable value for this parameter.
} 
this would require a large, delayed income effect toward services. This is not possible with the Stone-Geary preferences, where the endowments and subsistence requirements are most important at low levels of income. With little income effect late in the sample, the model does what it can with substitution. The fact that the relative share of services is rising faster than the relative price of services would require (non-quasiconcave) preferences in which households substitute toward the more expensive good. The best the model could do is calibrate Leontieff preferences.
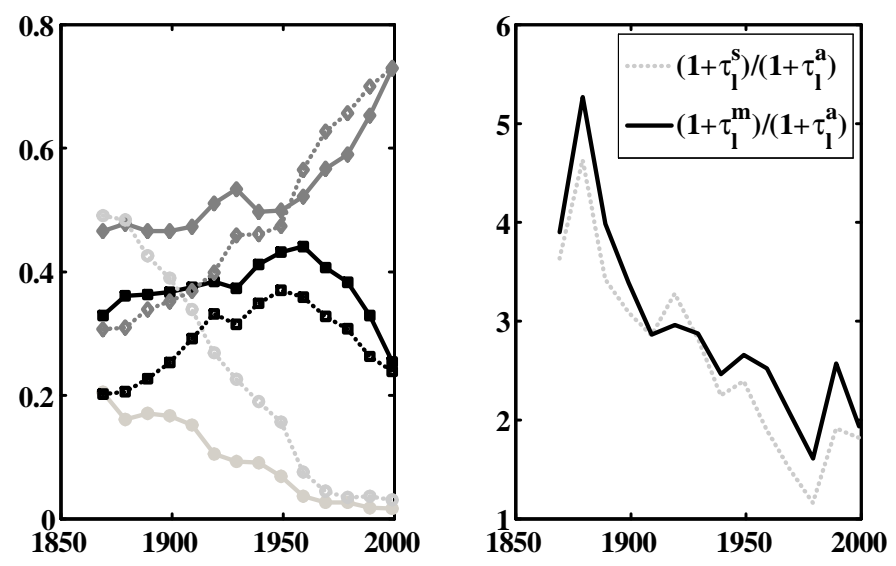

Figure 2: Panel a. Evolution of value-added shares (solid) vs. employment shares (dashed): agriculture (circles), manufacturing (squares), services (diamonds). United States, 1860-2000. Panel b. Implied relative human capital and sectoral factor distortions: manufacturing $\left(h_{m} / h_{a},\left(1+\tau_{l}^{m}\right) /\left(1+\tau_{l}^{a}\right)\right.$, solid) and services $\left(h_{s} / h_{a},\left(1+\tau_{l}^{s}\right) /\left(1+\tau_{l}^{a}\right)\right.$, dashed).

Figure 2 notes another important shortcoming in the model. Panel A shows the large deviation between value-added shares and labor shares, especially early in development. Recall that given Proposition 2, the standard model cannot explain this without sectoral differences in human capital or factor distortions. Panel B plots the implied relative labor distortions or, equivalently, relative human capital levels, which again are larger earlier in development. These distortions could indicate either a barrier into services and manufacturing and out of agriculture, larger human capital levels in services and manufacturing, lower human capital levels in agriculture, or some combination of the two.

Caselli and Coleman (2001) emphasize a trend in the U.S. between agri- 
culture and non-agriculture using the wedge in wages rather than output per worker. They model the initial gap as the result of frictions in obtaining education necessary for non-agriculture, and posit declining educational costs to explain the secular convergence. Hence, their model has aspects of both the distortions and human capital story, but it does not distinguished manufacturing and services.

\section{Conclusions}

We have highlighted shortcomings of traditional explanations of structural change. These puzzles call for new directions in structural change, many of which are already being pursued in the literature of New Structural Change. Models with sequential non-homotheticities (e.g., Buera and Kaboski, 2007, 2008; Foellmi and Zweimueller, 2006, 2008; Matsuyama, 2002), higher levels of disaggregation (e.g., Acemoglu and Guerrieri, 2008, Valentinyi and Herrendorf, 2007b), and home production (e.g., Buera and Kaboski, 2007, 2008; Rogerson, 2008) may better match the observed data on value-added shares. Models that incorporate the role of human capital (Buera and Kaboski, 2008) and/or sector specific distortions (Buera et al., 2008, Valentinyi and Herrendorf, 2007b, Restuccia et al., 2008) may be fruitful in explaining the divergence between labor and value-added shares. Empirical work is needed to distinguish between the roles of sector specific distortions and relative human capital levels by exploring data on labor income shares, while a theoretical justification is also needed to explain convergence of distortions and/or human capital levels over development. Research linking structural change to distortions, human capital, and home production may also give a more fundamental role of structural change, linking it to first-order effects on output, inequality, and organization of the family. Finally, an important avenue for further research is to imbed structural change into open economy models (Fieler, 2007; Matsuyama, 2008).

\section{References}

[1] Acemoglu, Daron and Guerrieri, Veronica "Capital Deepening and NonBalanced Economic Growth." Journal of Political Economy 116 (2008): 467-498. 
[2] Baumol, William J. "Macroeconomics of Unbalanced Growth: The Anatomy of the Urban Crisis," The American Economic Review 57 (1967) : 415-426.

[3] Buera, Francisco J., Joseph P. Kaboski, "The Rise of the Service Economy." mimeo, University of California at Los Angeles and Ohio State University, 2008.

[4] Buera, Francisco J., Joseph P. Kaboski, "Scale and the Origins of Structural Change." mimeo, University of California at Los Angeles and Ohio State University, 2008.

[5] Buera, Francisco J., Kaboski, Joseph P., and Yongseok Shin, "A Tale of Two Sectors." mimeo, University of California at Los Angeles, Ohio State University and University of Wisconsin at Madison, 2008.

[6] Caselli, Francesco, and Coleman, Wilbur John, II. "The U.S. Structural Transformation and Regional Convergence: A Reinterpretation." Journal of Political Economy 109 (2001): 584-616.

[7] Engel, Ernst, "Die Productions- und Consumptionsverhaeltnisse des Koenigsreichs Sachsen," Zeitschrift des Statistischen Buereaus des Koeniglich Saechsischen Ministeriums des Inneren, No. 8 und 9. Reprinted in the Appendix of Engel (1895).

[8] Fieler, Ana C., "Non-Homotheticity and Bilateral Trade: Evidence and a Quantitative Explanation," mimeo, New York University, 2007.

[9] Foellmi, Reto, and Joseph Zweimueller, "Structural Change and the Kaldor Facts of Economic Growth When Engel-curves are Non-linear." mimeo, University of Bern and University of Zurich, 2007.

[10] Foellmi, Reto, and Joseph Zweimueller, "Is Inequality Harnful for Innovation and Growth? Price Versus Market Size Effects." presented at the 2008 Congress of the European Economic Association, Milan, Italy.

[11] Herrendorf, Berthold, and Akos Valentinyi, "Measuring Factor Income Shares at the Sector Level." mimeo, Arizona State Univ., (2007a).

[12] Herrendorf, Berthold, and Akos Valentinyi, "Which Sectors Make the Poor Countries so Unproductive?" mimeo, Arizona State, (2007b).

[13] Houthakker, Hendrik S. "An International Comparison of Household Patterns, Commemorating the Century of Engel's Law," Econometrica, 25, 532-551, 1957. 
[14] Kongsamut, Piyabha, Rebelo, Sergio, and Danyang Xie. "Beyond Balanced Growth," Review of Economic Studies 68 (2001): 869-882.

[15] Matsuyama, Kiminori, "The Rise of Mass Consumption Societies," Journal of Political Economy 110 (2002): 1035-1070.

[16] Matsuyama, Kiminori, "Structural Change," in The New Palgrave Dictionary of Economics, Second Edition, edited by Steven N. Durlauf and Lawrence E. Blume, Palgrave McMillan, 2008.

[17] Matsuyama, Kiminori, "Structural Change in an Interdependent World: A Global View of Manufacturing Decline," presented at the 2008 Congress of the European Economic Association, Milan, Italy.

[18] Ngai, L. Rachel, and Christopher A. Pissarides. "Structural Change in a Multi-Sector Model of Growth," The American Economic Review, 97 (March 2007): 429-443.

[19] Restuccia, Diego, Yang, Dennis Tao, and Zhao, Xiaodong "Agriculture and aggregate productivity: A quantitative cross-country analysis" Journal of Monetary Economics 55 (2008) 234-250.

[20] Rogerson, Richard, "Structural Transformation and the Deterioration of European Labor Market Outcomes." Journal of Political Economy, 116 (April, 2008): 236-259. 